\title{
Detection of Early Right Ventricular Dysfunction in Young Patients With Thalassemia Major Using Tissue Doppler Imaging
}

\author{
Helen Bornaun, ${ }^{1, *}$ Reyhan Dedeoglu, ${ }^{2}$ Kazim Oztarhan, ${ }^{1}$ Savas Dedeoglu, ${ }^{3}$ Erkan Erfidan, ${ }^{4}$ Muge \\ Gundogdu, ${ }^{5}$ Gonul Aydogan, ${ }^{5}$ and Dicle Cengiz ${ }^{6}$ \\ ${ }^{1}$ Department of Pediatric Cardiology, Istanbul Kanuni Sultan Suleyman Training and Research Hospital, Istanbul, Turkey \\ ${ }^{2}$ Department of Pediatric Cardiology, Cerrahpasa Medical Faculty, Istanbul University, Istanbul, Turkey \\ ${ }^{3}$ Institute of Health Sciences, Uskudar University, Istanbul, Turkey \\ ${ }^{4}$ Department of Pediatrics, Istanbul Kanuni Sultan Suleyman Training and Research Hospital, Istanbul, Turkey \\ ${ }^{5}$ Department of Pediatric Hematology, Istanbul Kanuni Sultan Suleyman Training and Research Hospital, Istanbul, Turkey \\ ${ }^{6}$ Departments of Statistics, Istanbul Commerce University, Istanbul, Turkey \\ "Corresponding author: Helen Bornaun, Department of Pediatric Cardiology, Istanbul Kanuni Sultan Suleyman Training and Research Hospital, Istanbul, Turkey. Tel: \\ +90-5063433952, Fax: +90-2126320050, E-mail: helenbornaun@gmail.com
}

Received 2016 February 27; Revised 2016 April 11; Accepted 2016 April 30.

\begin{abstract}
Background: Myocardial iron overload is the most common cause of mortality in patients with thalassemia major (TM), also known as beta-thalassemia. T2* cardiovascular magnetic resonance imaging (MRI) is the best way of monitoring cardiac iron, and new echocardiographic techniques can be used to assess cardiac function.

Objectives: The aim of this study was to assess the systolic and diastolic right ventricular (RV) function of patients with TM using tissue Doppler imaging (TDI) and to determine whether this echocardiographic technique is an adequate diagnostic tool for the screening and detection of subclinical cardiac dysfunction.

Patients and Methods: Eighty-four patients with TM were evaluated by conventional echocardiography and pulse-wave TDI. The data of the TM group (Group 1) were compared with that of 85 age- and sex-matched healthy controls (Group 2). Cardiovascular T2* MRI examinations were performed in 49 of the 85 patients.

Results: The patients with TM had significantly lower values for weight, height, body mass index, systolic arterial pressure, deceleration time, E'/A', and ejection time (ET) than the controls. Group 1 also had significantly higher values for peak early diastolic velocity (E) over peak late diastolic velocity (A), peak early diastolic velocity of TDI (E'), peak late diastolic velocity of TDI (A'), E/E', isovolumetric relaxation time, isovolumetric contraction time, and RV magnetic perfusion imaging (MPI) than Group 2.

Conclusions: RV diastolic dysfunction occurs before systolic deterioration in patients with TM and cannot be screened with conventional echocardiographic techniques. In routine practice, TDI measurements, MPI (for global function) and the E/E' parameter (for diastolic function) can be used to screen and detect early RV dysfunction.
\end{abstract}

Keywords: Beta-Thalassemia, Young Patients, Ventricular Function, Echocardiography

\section{Background}

Thalassemia major (TM), also known as betathalassemia, is a hereditary anemia in which patients require lifelong blood transfusions to prolong survival (1). Although these transfusions are mandatory for life, the consequent iron accumulation in the endocrine organs, liver, and heart is a major cause of morbidity and mortality in patients with TM. In affected patients, myocardial iron overload eventually leads to congestive heart failure and is the most common cause of mortality in this population (2, 3). Chelation therapy is used to prevent iron overload as it can reduce iron accumulation in the organs. Nevertheless, this therapy cannot completely overcome myocardial involvement, and iron overload cardiomyopathy thus continues to be a leading cause of mortality in patients with TM in many centers $(4,5)$.

$\mathrm{T} 2{ }^{*}$ cardiovascular magnetic resonance imaging (MRI) is the best way of monitoring cardiac iron load. It allows the detection of cardiac iron overload prior to the occurrence of heart failure, and management strategies can therefore be started immediately. However, T2* MRI is expensive and is not available in many centers (6).

Assessments of cardiac iron load can be performed directly using T2* MRI or indirectly by evaluating ventricular volumes and examining the effects of myocardial iron load on cardiac function. New echocardiographic techniques such as tissue Doppler imaging (TDI) are widely available and can be used to assess cardiac function, as well as to screen and detect subclinical cardiac dysfunction (79). Left-sided heart failure is reported clinically more com- 
mon than right-sided heart failure, and right ventricular (RV) dysfunction develops earlier in asymptomatic TM patients (10).

\section{Objectives}

The aim of this study was to assess systolic and diastolic RV function with TDI echocardiography and to determine whether this echocardiographic technique is an adequate diagnostic tool for the screening and detection of subclinical cardiac dysfunction.

\section{Patients and Methods}

The subjects included in the study were asymptomatic patients with TM who had normal left ventricular (LV) global systolic function (ejection fraction [EF] of 55\% and fractional shortening of 30\%) by M-mode echocardiography. Between January and September 2015, 84 patients with TM who met these criteria were evaluated by conventional echocardiography and pulse-wave TDI (Group 1). The Group 1 data were compared with the data of a control group consisting of 85 age- and sex-matched controls (Group 2). Cardiovascular T2* MRI examinations were performed in 49 of the 85 patients with TM. All the patients were followed up in a pediatric hematology clinic. All the patients with TM were receiving regular blood transfusions to maintain serum hemoglobin levels above $10 \mathrm{~g} / \mathrm{dL}$ as well as long-term chelation therapy. The chelation therapy administered in this study consisted of deferoxamine (Desferal [DFO], Novartis Pharma AG, Basel, Switzerland) or deferasirox (Exjade [DFX], Novartis Pharma AG, Basel, Switzerland), or a combination of deferiprone (Ferriprox [DFP], Apotex Inc., Toronto, ON, Canada) and deferoxamine.

Patients with any cardiovascular symptoms, LV systolic dysfunction on echocardiography, history/evidence of congenital heart disease, or any rhythm abnormalities in their medical records, or who were receiving medications other than chelation therapy or had systemic diseases (including but not limited to renal diseases, pulmonary diseases, hypertension, and diabetes) were excluded from this study. Group 2 (controls) included ageand sex-matched healthy children referred to the pediatric outpatient clinic for reasons such as innocent heart murmur among other conditions, and these patients underwent physical and echocardiographic examinations. The institutional ethics committee approved the study. All the patients and/or their parents gave their informed consent. The study complied with the ethical rules for human experimentation stated in the declaration of Helsinki.
All the echocardiographic measurements were obtained using the same ultrasound equipment (S7 Pro, general electric, city, FL) with a $3 \mathrm{MHz}$ transducer. Standard transthoracic echocardiograms involve M-mode, twodimensional Doppler flow assessments (PW), and TDI index measurements and filtration (including pulsed-wave tissue Doppler imaging [PW-TDI]). The Nyquist limit was adjusted to between -15 and $20 \mathrm{~cm} /$ second. The gains were reduced until a clear tissue signal with minimal background noise was achieved. All the PW Doppler and PWTDI parameters were measured at a sweep speed of 100 $\mathrm{mm} / \mathrm{second}$ at the end of expiration and taken over an average of three consecutive heartbeats. All measurements were performed according to the recommendations of the American society of echocardiography (11). PW and PW-TDI echocardiography were performed to measure the peak early and the late diastolic flow velocities (E and A, respectively, cm/second) in the lateral tricuspid and transtricuspid annulus view, respectively. The left ventricular ejection fraction was calculated using the modified Simpson method (12). The isovolumetric RV relaxation time (IVRT) was determined by the difference between the time interval from the peak of the $\mathrm{R}$ wave on the electrocardiogram and the onset of the tricuspid valve opening and the time interval from the peak of the $\mathrm{R}$ wave and the end of the pulmonary systolic flow. The flow velocities of the superior vena cava and right upper pulmonary vein were also recorded. Echocardiographic examinations were performed in the left lateral decubitus, or supine position, during normal respiration. All the patients and controls' arterial blood pressure measurements and electrocardiogram tracings were in the normal ranges.

RV systolic function was assessed using fractional area change, tricuspid annular plane systolic excursion, pulsed TDI S' (reflecting the velocity of the tricuspid annular systolic motion), and the myocardial performance index (MPI). Combining more than one measure of RV function, such as S' (reference values for age: $14.2 \pm 2.3$ ) and MPI (reference values for age: $0.29 \pm 0.08$ ), was deemed to differentiate normal from abnormal function more reliably (13).

\subsection{Diastolic Function Recommendations (13)}

The measurement of RV diastolic function is considered in patients with suspected RV impairment as a marker of early or subtle RV dysfunction or in patients with known RV impairment as a marker of poor prognosis. The transtricuspid E/A ratio, E/E' ratio, and right atrium size have been validated the most and are thus the preferred measures. Tissue Doppler is less load-dependent because a reduction in preload causes an equal decrease in E' and A' and therefore results in an unchanged E'/A' ratio. 


\subsection{Grading of RV Diastolic Dysfunction}

A tricuspid E/A ratio $<0.8$ suggests impaired relaxation in adults (normal ranges in children between 12 - 18 years: $1.88 \pm 0.56$ ). A tricuspid E/A ratio ranging from 0.8 to 2.1 with an $\mathrm{E} / \mathrm{E}^{\prime}$ ratio $>6$ or diastolic flow predominance in the hepatic veins suggests pseudonormal filling in adults (normal range in children: $3.7 \pm 1.0,95 \%$ confidence interval $[ \pm$ $2 \mathrm{SD}$ : 3.5 -3.9) (14). A tricuspid E/A ratio $>2.1$ with a deceleration time $<120 \mathrm{~ms}$ suggests restrictive filling.

\subsection{Evaluation of Myocardial Function and Myocardial Iron Load by $\mathrm{T}^{*}$ Cardiovascular MRI}

Our patients' T2* MRI assessments were performed at the Department of Radiology one week after undergoing a blood transfusion. A Siemens 1.5-Tesla MRI device (Symphony, Siemens, Erlangen, Germany) was used. This MRI evaluation method helps detect iron load because organs containing iron darken more rapidly. The myocardial T2* MRI was conducted with a cardiac-gated, singlebreathhold, eight-echo sequence (2.6 - $16.7 \mathrm{~ms}$ ) to image a single midventricular short axis slice. The intensity was measured and analyzed for each echo-time ventricular signal. The ventricular dimensions and function were assessed by long- and short-axis cines. The $\mathrm{T} 2 *$ analysis was performed using Thalassemia Tools (a plug-in for cardiac MRI tools, cardiovascular imaging solutions, London, UK) with curve truncation to account for background noise (15). Patients were considered at high risk for cardiac complications if their T2* MRI values were $<10 \mathrm{~ms}$, at medium risk if their TR2* values were between $10-20 \mathrm{~ms}$, and at low risk if their T2* MRI values were $>20 \mathrm{~ms}$ (16).

The cardiac iron concentration calculation from the cardiovascular $\mathrm{T} 2{ }^{*} \mathrm{MRI}$ results was performed as follows: $[\mathrm{Fe}]=4.5(\mathrm{~T} 2 *)-1.22$, where Fe is the cardiac iron concentration in milligrams per gram of dry weight (17). The same radiologist evaluated all the MRI studies and was blind to the echocardiographic and TDI results.

\subsection{Statistical Analysis}

All the statistical analyses were performed using statistical package for the social sciences (SPSS) for windows version 17 software. The data analyses were performed by an experienced statistician. Continuous variables were expressed as mean \pm standard deviation (SD) (range), and the intergroup differences were analyzed by the Student's t-test or the Mann-Whitney U test. The relationships between the myocardial velocities and the other parameters were assessed using Pearson's correlation coefficient (r).

\section{Results}

The demographic and clinical features of the patients with TM and the healthy controls are presented in Table 1. There were no significant differences between the two groups in terms of age and sex. The patients with TM had significantly lower values for weight $(\mathrm{P}=0.02)$, height $(\mathrm{P}=$ $0.04)$, body mass index $(\mathrm{P}=0.04)$, and systolic arterial pressure $(\mathrm{P}=0.02)$ than the controls (Table 1$)$.

4.1. Conventional Echocardiographic Measurements of the Patients With TM and the Controls

The Group 1 patients had larger RV diameter (RVD) values at the basal and mid-ventricle levels in the fourchamber transthoracic views than the Group 2 patients $(\mathrm{P}=0.001)$. Compared to the Group 2 patients, the patients with TM also had higher values for RV anterior wall thickness diameter $(\mathrm{P}=0.001)$, peak tricuspid regurgitant velocity (TRV) $(P=0.001)$, the ratio of peak TRV to the time-velocity integral (TVI) at the RV outflow tract (TRV/TVI $\mathrm{RVOT})(\mathrm{P}=0.001)$, pulmonary vascular resistance $(\mathrm{PVR})(\mathrm{P}=$ 0.001), inferior vena cava diameter $(\mathrm{P}=0.04)$, right atrial pressure (RAP) $(\mathrm{P}=0.001)$, RV pressure $(\mathrm{P}=0.001)$, pulmonary capillary wedge pressure $(\mathrm{PCWP})(\mathrm{P}=0.001)$, and $\mathrm{E}(\mathrm{P}=0.001)$ (Table 1$)$

\subsection{Doppler Echocardiographic Measurements of the Patients with TM and the Controls}

The Group1 patients had significantly higher values for $\mathrm{E} / \mathrm{A}(\mathrm{P}=0.001), \mathrm{E}^{\prime}(\mathrm{P}=0.001), \mathrm{A}^{\prime}(\mathrm{P}=0.001), \mathrm{E} / \mathrm{E}^{\prime}(\mathrm{P}=0.001)$, $\operatorname{IVRT}(P=0.001)$, isovolumetric contraction time $(P=0.001)$, $\mathrm{RV}$ myocardial performance index $(\mathrm{MPI})(\mathrm{P}=0.001)$, and a lower deceleration time (DT) $(\mathrm{P}=0.001), \mathrm{E}^{\prime} / \mathrm{A}^{\prime}(\mathrm{P}=0.001)$, and ejection time $(\mathrm{ET})(\mathrm{P}=0.001)$ than the Group 2 patients (Table 2).

Forty-nine of the patients underwent an MRI. Using T2* cardiovascular MRI, an abnormal myocardial iron load (T2* MRI $<20 \mathrm{~ms}$ ) was detected in 18\% (9/49) of the patients (Group 1a), and among these, 6\% (3/49) had severe (T2* MRI $<10 \mathrm{~ms}$ ) iron overload. Myocardial iron (T2* MRI > $20 \mathrm{~ms}$ ) was detected in $81 \%$ (40/49) of the patients (Group 1b). The patients in Group 1a had significantly higher blood ferritin levels than those in Group $1 \mathrm{~b}(\mathrm{P}=0.02)$.

4.3. Conventional and Doppler Echocardiographic Measurements of the TM Patients Categorized by $T 2 *$ Cardiovascular MRI

RV diastolic dysfunction was more prominent in the patients with iron overload than those without (Table 3). The following Doppler measurements were higher in Group 1a than in Group 1b: TVI at RVOT $(\mathrm{P}=0.06)$, TRV to TVI RVOT $(P=0.026), \operatorname{PVR}(P=0.026)$, E' $(P=0.068), E / E^{\prime}(P$ 


\begin{tabular}{|c|c|c|c|}
\hline Variable & Patients (84) & PControls (85) & PP \\
\hline \multicolumn{4}{|l|}{ Gender } \\
\hline Female & 49 & 49 & \\
\hline Male & 35 & 36 & \\
\hline Age, $y$ & $13.2 \pm 3.2$ & $13.05 \pm 5.3$ & 0.882 \\
\hline Weight, kg & $38.2 \pm 18.8$ & $45 \pm 21.2$ & 0.002 \\
\hline Length, $\mathbf{c m}$ & $139.3 \pm 26.2$ & $147.8 \pm 27.7$ & 0.044 \\
\hline Body mass index & $18.1 \pm 3.6$ & $19.3 \pm 3.8$ & 0.048 \\
\hline Heart rate, beats/minute ${ }^{-1}$ & $92.2 \pm 15.5$ & $83.8 \pm 20.0$ & 0.003 \\
\hline Systolic arterial pressure, mmHg & $99.4 \pm 12.0$ & $103.6 \pm 11.8$ & 0.025 \\
\hline Diastolic arterial pressure, $\mathrm{mmHg}$ & $55.0 \pm 10.2$ & $56.9 \pm 9.9$ & 0.217 \\
\hline \multicolumn{4}{|l|}{ Conventional echocardiographic measurements } \\
\hline $\mathrm{RV}$ basal, $\mathrm{cm}$ & $3.9 \pm 0.7$ & $3.5 \pm 0.55$ & $0.001^{\mathrm{b}}$ \\
\hline $\mathrm{RV}$ mid, $\mathrm{cm}$ & $3.09 \pm 0.5$ & $2.8 \pm 0.41$ & $0.0001^{\mathrm{b}}$ \\
\hline $\mathrm{RV}$ posterior wall diameter, $\mathrm{cm}$ & $4.6 \pm 1.0$ & $3.9 \pm 0.7$ & $0.0001^{\mathrm{b}}$ \\
\hline $\mathrm{RV}$ area, $\mathrm{cm}^{2}$ & $19.3 \pm 6.8$ & $16.5 \pm 5.3$ & $0.003^{\mathrm{b}}$ \\
\hline Peak tricuspid regurgitant velocity (TRV) & $2.7 \pm 0.2$ & $2.03 \pm 0.21$ & $0.0001^{b}$ \\
\hline RV systolic pressure from TR jet velocity, $\mathrm{mmHg}$ & $29.9 \pm 5.5$ & $16.73 \pm 3.34$ & $0.0001^{\mathrm{b}}$ \\
\hline Time velocity integral (TVI) at RVOT & $18.0 \pm 1.6$ & $20.1 \pm 2.1$ & $0.0001^{b}$ \\
\hline TRV/TVI RVOT & $0.15 \pm 0.01$ & $0.10 \pm 0.01$ & $0.0001^{b}$ \\
\hline PVR(Wood units) & $1.6 \pm 0.1$ & $1.17 \pm 0.13$ & $0.0001^{\mathrm{b}}$ \\
\hline Inferior vena cava diameter, $\mathrm{cm}$ & $16.4 \pm 3.9$ & $15.2 \pm 3.7$ & $0.046^{\mathrm{b}}$ \\
\hline Right atrial pressure, mmHg & $5.3 \pm 1.0$ & $5.00 \pm 0.00$ & $0.0001^{\mathrm{b}}$ \\
\hline Right ventricular pressure, $\mathrm{mmHg}$ & $35.3 \pm 5.6$ & $21.7 \pm 3.3$ & $0.0001^{\mathrm{b}}$ \\
\hline Pulmonary capillary wedge pressure, $\mathrm{mmHg}$ & $10.1 \pm 1.7$ & $8.0 \pm 1.0$ & $0.0001^{\mathrm{b}}$ \\
\hline TAPSE, $\mathrm{cm} / \mathrm{s}^{-1}$ & $2.1 \pm 0.1$ & $2.2 \pm 0.07$ & $0.0001^{\mathrm{b}}$ \\
\hline
\end{tabular}

${ }^{\mathrm{a}}$ TAPSE: Measurement of tricuspid annular plane systolic excursion.

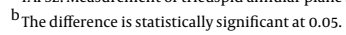

$=0.03)$, ET $(P=0.068)$, and MPI $(P=0.06) . \mathrm{E} / \mathrm{E}^{\prime}$ and ET had positive linear correlations with the $\mathrm{T} 2^{*} \mathrm{MR}<20$ values $(\mathrm{r}$ $=0.44, \mathrm{P}=0.023$ and $\mathrm{r}=0.54, \mathrm{P}=0.004$, respectively). Additionally, E' had a negative linear correlation $(\mathrm{r}=-0.33, \mathrm{P}=$ 0.023 ) with the values of $22^{*} \mathrm{MRI}<20$.

\section{Discussion}

In this study, the young patients with TM and normal systolic LV function exhibited an abnormal RV relaxation filling pattern, which was detected with TDI. Additionally, the best prognostic parameter of diastolic function was the RV anterior wall E/E' ratio, which increased concomitantly with the impaired relaxation-pseudonormalization stage in the patients with TM. Further, the patients with TM showed global impairment of RV function with MPI, which may be suggestive of early cardiac function impairment.

Myocardial iron overload eventually leads to congestive heart failure and is the most common cause of mortality among patients with TM (2). T2* MRI is the best way of monitoring cardiac iron load. Using this method, cardiac iron overload can be detected prior to the occurrence of heart failure, and management strategies such as chelation therapy can be started immediately. Nevertheless, cardiac T2* MRI is expensive and therefore not available in many centers. New echocardiography techniques for the assessment of cardiac function are however widely available and can be used for the screening and detection of subclinical cardiac dysfunction (7). Left-sided heart failure is reported clinically more common than right-sided heart failure. However, in necropsy studies of patients with TM, the RV and LV were affected equally in terms of hypertrophy and myocyte disruption $(18,19)$. Furthermore, an RV with thin walls may be more prone to rapid and earlier dysfunction (20). There are different suggested pathologies in RV dysfunction: volume overload secondary to chronic anemia, and myocardial iron involvement and cardiomyopathy in which the myocytes are affected by the iron overload (7, 21). RV dysfunction seems to develop earlier in asymptomatic patients with TM. In our patients with $\mathrm{TM}$, the increasing RV dimensions, lower blood pressure, 
Table 2. Doppler Echocardiographic Measurements of the Thalassemia Major Patients and the Healthy Controls

\begin{tabular}{|c|c|c|c|}
\hline Doppler Measurements & Patients & Controls & $\mathbf{P}$ \\
\hline Tricuspid E, cm/second ${ }^{-1}$ & $82 \pm 0.1$ & $64 \pm 0.07$ & $0.000^{\mathrm{a}}$ \\
\hline Tricuspid A, cm/second ${ }^{-1}$ & $63 \pm 9.4$ & $53 \pm 0.03$ & 0.233 \\
\hline Tricuspid E/A & $1.3 \pm 0.2$ & $1.6 \pm 0.12$ & $0.000^{\mathrm{a}}$ \\
\hline DT, ms & $144.0 \pm 17.4$ & $166.2 \pm 20.4$ & $0.000^{\mathrm{a}}$ \\
\hline \multicolumn{4}{|l|}{ Tissue Doppler measurements } \\
\hline $\mathrm{E}^{\prime}, \mathrm{cm} / \mathrm{s}^{-1}$ & $19 \pm 1$ & $16 \pm 0.01$ & $0.000^{\mathrm{a}}$ \\
\hline$A^{\prime}, \mathrm{cm} / \mathrm{s}^{-1}$ & $14 \pm 0.2$ & $10 \pm 0.00$ & $0.000^{\mathrm{a}}$ \\
\hline$E^{\prime} / A^{\prime}$ & $1.38 \pm 0.3$ & $1.6 \pm 0.22$ & $0.000^{\mathrm{a}}$ \\
\hline $\mathrm{s}^{\prime}, \mathrm{cm} / \mathrm{s}^{-1}$ & $16.2 \pm 0.01$ & $17 \pm 0.03$ & 0.321 \\
\hline $\mathrm{E} / \mathrm{E}^{\prime}$ & $4.2 \pm 0.5$ & $3.5 \pm 0.3$ & $0.000^{\mathrm{a}}$ \\
\hline Ejection time & $263.0 \pm 19.4$ & $278.4 \pm 20.0$ & $0.000^{\mathrm{a}}$ \\
\hline $\mathrm{IVCT}, \mathrm{ms}$ & $40.63 \pm 5.7$ & $34.8 \pm 6.4$ & $0.000^{\mathrm{a}}$ \\
\hline IVRT, ms & $67.4 \pm 15.7$ & $53.8 \pm 7.7$ & $0.000^{\mathrm{a}}$ \\
\hline RVMPI & $41 \pm 0.08$ & $32 \pm 0.03$ & $0.000^{\mathrm{a}}$ \\
\hline Doppler echocardiographic measurements in subgroups & Group 1a, $\mathrm{T}^{*}<20 \mathrm{~ms}$ & Group $1 \mathrm{~b}, \mathrm{~T} 2^{*}>20 \mathrm{~ms}$ & \\
\hline Tricuspid E, cm/second ${ }^{-1}$ & $86.7 \pm 0.13$ & $8.4 \pm 1.1$ & 0.577 \\
\hline Tricuspid A, cm/second ${ }^{-1}$ & $63.3 \pm 0.17$ & $2.8 \pm 0.1$ & 0.638 \\
\hline Tricuspid E/A & $1.4 \pm 0.23$ & $1.3 \pm 0.2$ & 0.308 \\
\hline $\mathrm{DT}, \mathrm{ms}$ & $144.2 \pm 21.2$ & $150.6 \pm 18.2$ & 0.423 \\
\hline \multicolumn{4}{|l|}{ Tissue Doppler echocardiographic measurements } \\
\hline $\mathrm{E}^{\prime}, \mathrm{cm} /$ second $^{-1}$ & $21.2 \pm 3.5$ & $19.6 \pm 2.0$ & $0.068^{\mathrm{b}}$ \\
\hline$A^{\prime}, \mathrm{cm} /$ second $^{-1}$ & $15.5 \pm 4.1$ & $15.2 \pm 3.4$ & 0.787 \\
\hline$E^{\prime} / A^{\prime}$ & $1.4 \pm 0.2$ & $1.3 \pm 0.2$ & 0.467 \\
\hline $\mathrm{S}^{\prime}, \mathrm{cm} /$ second $^{-1}$ & $18.7 \pm 1.09$ & $18.0 \pm 1.5$ & 0.189 \\
\hline $\mathrm{E} / \mathrm{E}^{\prime}$ & $4.3 \pm 0.5$ & $4.1 \pm 0.3$ & 0.225 \\
\hline $\mathrm{E}^{\prime}$ deceleration time, $\mathrm{cm} /$ second $^{-1}$ & $4.09 \pm 0.3 .0$ & $4.3 \pm 0.5$ & 0.255 \\
\hline $\mathrm{ET}, \mathrm{cm} /$ second $^{-1}$ & $267.0 \pm 19.6$ & $255.2 \pm 17.0$ & $0.063^{\mathrm{b}}$ \\
\hline IVCT, ms & $45.1 \pm 6.5$ & $44.1 \pm 7.9$ & 0.738 \\
\hline IVRT, ms & $79.6 \pm 14.1$ & $73.8 \pm 0.28 .3$ & 0.277 \\
\hline Tissue Doppler MPI RV & $49.2 \pm 7.6$ & $44.3 \pm 6.9$ & $0.066^{\mathrm{b}}$ \\
\hline
\end{tabular}

and higher heart rates may have been caused by volume overload secondary to chronic anemia, which is consistent with previous reports $(7,8,22)$.

\subsection{RV Systolic Function}

There are only a few reported studies about RV function in TM patients. In each study, different variables were used to evaluate RV function (Table 4). It has also been reported that tricuspid annular systolic velocity is a useful parameter for the assessment of RV systolic function and can be used reliably regardless of the degree of pulmonary hypertension (23).

In the present study, we evaluated systolic RV and myocardial and annular velocities, which are determinants of systolic performance. However, when these parameters were compared between patients with TM and normal subjects, no significant differences were detected, indicating normal systolic performance. Additionally, despite categorizing the patients with TM into two groups according to T2* MRI, we did not find any significant difference in systolic function between the groups. Our results were consistent with those of Hamdy et al. (8), in whose study normal subjects were compared with patients with high ferritin levels. Hamdy et al. found that the patients with higher ferritin levels presented compromised systolic RV function. In contrast, our TM patients with higher iron overload and higher ferritin levels had values of $\mathrm{T}^{*} \mathrm{MRI}<20 \mathrm{~ms}$. The authors explained these differences by the pattern of iron deposition in the lungs, which leads to pulmonary hypertension, but can also cause myopathic changes in the car- 
Table 3. Clinical, Laboratory, and Conventional Echocardiographic Findings of Myocardial Iron Load in Thalassemia Major Patients Categorized Using T2* Cardiovascular MR

\begin{tabular}{|c|c|c|c|}
\hline Variables & Group 1a, $\mathrm{T2}^{*}<20 \mathrm{~ms}$ & Group $1 \mathrm{~b}, \mathrm{T2}^{*}>20 \mathrm{~ms}$ & $\mathbf{P}$ \\
\hline Age, $y$ & $17.6 \pm 6.3$ & $17.5 \pm 5.2$ & 0.954 \\
\hline Weight, kg & $45.3 \pm 15.2$ & $49.8 \pm 12.9$ & 0.363 \\
\hline Length, $\mathrm{cm}$ & $148.9 \pm 17.3$ & $156.8 \pm 14.8$ & 0.167 \\
\hline Body surface area, $\mathbf{m}^{2}$ & $1.3 \pm 0.31$ & $1.4 \pm 0.2$ & 0.282 \\
\hline Heart rate, beats/minute ${ }^{-1}$ & $82.5 \pm 12.2$ & $88.4 \pm 13.4$ & 0.234 \\
\hline Systolic arterial pressure, mmHg & $102.4 \pm 12.2$ & $104.4 \pm 10.0$ & 0.602 \\
\hline Diastolic arterial pressure, $\mathbf{m m H g}$ & $57.7 \pm 14.8$ & $58.02 \pm 9.35$ & 0.949 \\
\hline Hemoglobin, $g / \mathbf{d L}^{-1 a}$ & $10.4 \pm 1.5$ & $10.1 \pm 0.9$ & 0.457 \\
\hline Serum ferritin, $\mathbf{n g} / \mathbf{m L}^{-1}$ & $3766.3 \pm 2535.2$ & $1398.03 \pm 990.43$ & $0.023^{\mathrm{a}}$ \\
\hline \multicolumn{4}{|l|}{ Conventional echocardiographic measurements } \\
\hline Peak tricuspid regurgitant velocity (TRV) & $2.7 \pm 0.3$ & $2.7 \pm 0.2$ & 0.949 \\
\hline RV systolic pressure from TR jet velocity (mmHg) & $30.9 \pm 6.7$ & $30.6 \pm 4.5$ & 0.898 \\
\hline Time-velocity integral (TVI) at RVOT & $19.3 \pm 1.2$ & $17.8 \pm 1.4$ & $0.006^{\mathrm{a}}$ \\
\hline TRV/TVI RVOT & $0.15 \pm 0.01$ & $0.14 \pm 0.01$ & $0.026^{\mathrm{a}}$ \\
\hline PVR (Wood units) & $1.71 \pm 0.13$ & $1.59 \pm 0.15$ & $0.026^{\mathrm{a}}$ \\
\hline IVC diameter, mm & $18.8 \pm 2.7$ & $18.7 \pm 2.8$ & 0.961 \\
\hline Right atrial systolic pressure, mmHg & $5.3 \pm 1.0$ & $5.6 \pm 1.2$ & 0.454 \\
\hline Right ventricularl systolic pressure, $\mathrm{mmHg}$ & $36.2 \pm 6.5$ & $36.3 \pm 4.7$ & 0.956 \\
\hline Pulmonary cappilary wedge pressure, $\mathrm{mmHg}$ & $10.6 \pm 0.9$ & $10.3 \pm 1.5$ & 0.487 \\
\hline TAPSE, cm/second ${ }^{-1}$ & $2.15 \pm 0.16$ & $2.1 \pm 0.1$ & 0.659 \\
\hline $\mathrm{RV}$ posterior wall diameter, $\mathrm{cm}$ & $4.89 \pm 1.06$ & $5.2 \pm 0.7$ & 0.290 \\
\hline \multicolumn{4}{|l|}{ Left ventricular measurements } \\
\hline LV myocardial mass, $\mathrm{g}$ & $218.5 \pm 69.8$ & $231.9 \pm 77.0$ & 0.634 \\
\hline LVEDD, $\mathrm{mm}$ & $46.77 \pm 4.4$ & $47.2 \pm 5.3$ & 0.816 \\
\hline LVESD, mm & $29.1 \pm 2.7$ & $29.3 \pm 3.6$ & 0.840 \\
\hline IVS(d), mm & $8.8 \pm 1.5$ & $9.5 \pm 1.3$ & 0.182 \\
\hline $\operatorname{LVPWD}(\mathrm{d}), \mathrm{mm}$ & $7.7 \pm 1.9$ & $8.3 \pm 1.4$ & 0.306 \\
\hline LVEDV, $\mathrm{mm}^{3}$ & $102.4 \pm 24.1$ & $105.5 \pm 27.9$ & 0.758 \\
\hline LVESV, $\mathrm{mm}^{3}$ & $32.7 \pm 7.1$ & $42.0 \pm 45.4$ & 0.547 \\
\hline Stroke volume, $\mathrm{mL}$ & $69.5 \pm 18.1$ & $71.2 \pm 20.5$ & 0.823 \\
\hline
\end{tabular}

diac muscle. Systolic impairment may be masked by the effect of volume overload secondary to chronic anemia. Although our patients had similar ages, this discrepancy may be explained by the different stratification strategies in each study. Hamdy et al. grouped their patients according to ferritin levels. In contrast, we used $\mathrm{T} 2{ }^{*} \mathrm{~B}>20$ and $<$ $20 \mathrm{~ms}$ to grade myocardial iron overload.

Vogel et al. (7) concluded that clinically asymptomatic patients with myocardial iron overload have abnormal global longitudinal function. They stated that wall motion abnormalities may be a reflection of early myocardial damage, which is detectable via a common, useable echocardiographic method. They used MRI as the comparative gold standard to TDI and found a significant correlation between the presence of wall motion abnormalities and abnormal iron loading of the myocardium. They grouped patients similarly to the categorization in our study. They indicated that wall motion abnormalities were present in 33 of the $38(88 \%)$ patients with an abnormal myocardial iron load and in five of the 14 (35\%) patients with a normal T2* MRI $(\mathrm{P}<0.04)$. Notwithstanding, abnormal RV myocardial wall motion was present in only three patients in their study. Thus, it is possible that systolic derangement only occurs with greater disease progression and greater myocyte iron deposition. We recommend further longitudinal studies on a larger series of patients with TM to clarify these discrepancies.

\subsection{Diastolic Function}

Tissue Doppler is less load-dependent because a reduction in the preload causes an equal decrease in $\mathrm{E}^{\prime}$ and $\mathrm{A}^{\prime}$ and therefore an unchanged $E^{\prime} / A^{\prime}$ ratio. It has been reported that transtricuspid E/A ratio, E/E' ratio, and RA size 


\begin{tabular}{|c|c|c|c|c|c|c|}
\hline Variables & \multicolumn{2}{|c|}{ Current Study } & Hahalis (22) Am Heart J 2001 & Hahalis (24) Eur Heart J 2002 & Hamdy (8) Echocard Iography 2007 & Noori (25) Anadolu Kardiyol 2010 \\
\hline Patient, No. & \multicolumn{2}{|c|}{85} & 79 & 26 & 30 & 80 \\
\hline Age, $y$ & \multicolumn{2}{|c|}{$13.2 \pm 7.10$} & $24 \pm 8$ & $25.1 \pm 6.4$ & $11.7 \pm 5.1$ & $7.33 \pm 1.95$ \\
\hline RVED, cm & \multicolumn{2}{|c|}{$3.92 \pm 0.72$} & & $3.0 \pm 0.7$ & $2.2 \pm 0.3$ & \\
\hline \multicolumn{3}{|l|}{ RVDD, cm } & & & $1.8 \pm 0.3$ & \\
\hline $\mathrm{s}^{\prime}, \mathrm{cm} / \mathrm{s}^{-1}$ & \multicolumn{2}{|c|}{$17.61 \pm 11$} & & & $11.4 \pm 2.0$ & \\
\hline RVFS & & & & & $19.4 \pm 6.3$ & \\
\hline TAPSE, $\mathrm{cm} / \mathrm{s}^{-1}$ & \multicolumn{2}{|c|}{$2.1 \pm 0.1$} & & & & \\
\hline \multicolumn{7}{|l|}{ RV diastolic functions } \\
\hline $\mathrm{E}, \mathrm{cm} / \mathrm{s}^{-1}$ & $82.62 \pm 11$ & $19 \pm 1.9$ & $65 \pm 13$ & & $12.7 \pm 2.2$ & $62.33 \pm 20.13$ \\
\hline $\mathrm{A}, \mathrm{cm} / \mathrm{s}^{-1}$ & $16.46 \pm 9.42$ & $14 \pm 0.1$ & $52 \pm 13$ & & $9.2 \pm 2.4$ & $48.83 \pm 14.77$ \\
\hline $\mathrm{DT}, \mathrm{ms}$ & \multicolumn{2}{|c|}{$144.01 \pm 17.42$} & $200 \pm 42$ & $137 \pm 36$ & & $103 \pm 17$ \\
\hline $\mathrm{E} / \mathrm{E}^{\prime}, \mathrm{cm} / \mathrm{s}^{-1}$ & \multicolumn{2}{|c|}{$4.34 \pm 0.45$} & & & & \\
\hline IVRT & \multicolumn{2}{|c|}{$74.4 \pm 14.0$} & $29 \pm 11$ & $46 \pm 25$ & & $129 \pm 31$ \\
\hline MPI RV & \multicolumn{2}{|c|}{$41.24 \pm 0.08$} & & & & $0.66 \pm 0.29$ \\
\hline
\end{tabular}

Abbreviations: A, peak late diastolic velocity; E, peak early diastolic velocity; IVCT,
diastolic velocity; A', late diastolic velocity; MPI, myocardial performance index.

are the most validated, and thus preferred, measures to assess RV diastolic function (13).

The subgroup of our patients with T2* MRI $<20$ manifested a greater increase in E' and E/E' and a higher TRV/TVI RVOT and PVR level. We suggest that RV involvement in patients with TM presents early in the course of the disease and that it is caused by the impairment of diastolic performance, with pattern changes pointing toward impaired relaxation. Notwithstanding, we found that the TVI RVOT, PVR, and RAP values in the patients with TM were higher than in the normal subjects. Moreover, this increasing trend was consistent with disease progression, and the values were under the cutoff range for pulmonary artery hypertension.

In Hahalis et al.'s (24) study, the majority of patients with TM and heart failure exhibited severe RV dysfunction, independent of pulmonary artery pressure. They used the right atrial-to-PCWP ratio to assess the disproportional rise in RV filling pressure, the less severe elevation of pulmonary artery pressure, and the slight decline of cardiac output after volume challenges. The authors suggested that their findings were indicative of severe right chamber involvement with poor force generation and an exhausted preload reserve. Their catheterization data showed that PVR was only mildly elevated, even in the patients in the worst functional classes. Although their patients were adults with heart failure, they showed that RV dysfunction was disproportionate to pulmonary hypertension. Their results were congruent with our findings of disproportionate diastolic dysfunction and pulmonary artery pressure, which, although high, was still under pulmonary hypertension limits.

Hahalis et al. (22) concluded that in patients with homozygous TM without cardiac disease, the pattern of RV filling is abnormal, indicating impaired RV relaxation. They indicated that a short DT of early tricuspid inflow has important prognostic value. Furthermore, their echocardiographic data did not differ between the subgroups comprising optimal versus non-optimal ferritin levels or with good versus moderate or insufficient chelation therapy, and the serum ferritin levels did not correlate with any echocardiographic parameters. Although in our study the DT was significantly different in the patients with TM than in the control group, the DT duration was within the normal range. Besides, there was no significant difference between the subgroups of patients with myocardial iron overload on MRI.

\subsection{Study Limitations}

In this study, we tried to evaluate the RV function of patients with TM. Although we used pediatric reference values for systolic and diastolic function (14), these values were not obtained from a large sample of patients. Notably, racial differences may occur. Particularly for the grading of the diastolic function of the right ventricle, there is no validated cutoff value for children as there is for adults.

\subsection{Conclusion}

In young patients with TM, RV dysfunction seems to develop at an early age, long before the effects of pulmonary 
hypertension are established. As RV diastolic dysfunction occurs before systolic deterioration and thus cannot be screened with conventional echocardiographic techniques, TDI parameters, MPI (for global function), and the E/E' parameter (for diastolic function) can be used in routine clinical practice for the screening and detection of early RV dysfunction.

\section{Footnotes}

Authors' Contribution: All the authors were involved in drafting or revising the article critically for important intellectual content. All the authors approved the final version submitted for publication. Helen Bornaun had full access to all the data and assessed the accuracy of the data analysis. The authors' further contributions were as follows: study design, Helen Bornaun, Reyhan Dedeoglu, and Kazim Oztarhan; acquisition of data, Savas Dedeoglu, Erkan Erfidan, Muge Gundogdu, Gonul Aydogan, and Dicle Cengiz; analysis and interpretation of data, Helen Bornaun, Reyhan Dedeoglu, and Dicle Cengiz.

Funding/Support: No funding was received from any public, special, or commercial sector for the development of this manuscript.

\section{References}

1. Weatherall DJ, Clegg JB. The thalassaemia syndromes. John Wiley and Sons; 2008.

2. Borgna-Pignatti C, Rugolotto S, De Stefano P, Piga A, Di Gregorio F, Gamberini MR, et al. Survival and disease complications in thalassemia major. Ann NYAcad Sci. 1998;850:227-31. [PubMed: 9668544].

3. Li CK, Luk CW, Ling SC, Chik KW, Yuen HL, Li CK, et al. Morbidity and mortality patterns of thalassaemia major patients in Hong Kong: retrospective study. Hong Kong Med J. 2002;8(4):255-60. [PubMed: 12167729].

4. Modell B, Khan M, Darlison M, Westwood MA, Ingram D, Pennell DJ. Improved survival of thalassaemia major in the UK and relation to T2* cardiovascular magnetic resonance. J Cardiovasc Magn Reson. 2008;10:42. doi: 10.1186/1532-429X-10-42. [PubMed: 18817553].

5. Olivieri NF, Nathan DG, MacMillan JH, Wayne AS, Liu PP, McGee A, et al. Survival in medically treated patients with homozygous beta-thalassemia. $N$ Engl J Med. 1994;331(9):574-8. doi: 10.1056/NEJM199409013310903. [PubMed: 8047081].

6. Kirk P, Roughton M, Porter JB, Walker JM, Tanner MA, Patel J, et al. Cardiac T2* magnetic resonance for prediction of cardiac complications in thalassemia major. Circulation. 2009;120(20):1961-8. doi: 10.1161/CIRCULATIONAHA.109.874487. [PubMed: 19801505].

7. Vogel M, Anderson LJ, Holden S, Deanfield JE, Pennell DJ, Walker JM. Tissue Doppler echocardiography in patients with thalassaemia detects early myocardial dysfunction related to myocardial iron overload. Eur Heart J. 2003;24(1):113-9. [PubMed: 12559943].

8. Hamdy AM. Use of strain and tissue velocity imaging for early detection of regional myocardial dysfunction in patients with beta thalassemia. Eur J Echocardiogr. 2007;8(2):102-9. doi: 10.1016/j.euje.2006.02.004. [PubMed: 16564231].

9. Magri D, Sciomer S, Fedele F, Gualdi G, Casciani E, Pugliese P, et al. Early impairment of myocardial function in young patients with beta-thalassemia major. Eur J Haematol. 2008;80(6):515-22. doi 10.1111/j.1600-0609.2008.01054.x. [PubMed: 18284626].

10. Kremastinos DT, Tsetsos GA, Tsiapras DP, Karavolias GK, Ladis VA, Kattamis CA. Heart failure in beta thalassemia: a 5-year follow-up study. Am J Med. 2001;111(5):349-54. [PubMed: 11583636].

11. Quinones MA, Otto CM, Stoddard M, Waggoner A, Zoghbi WA, Doppler Quantification Task Force of the N, et al. Recommendations for quantification of Doppler echocardiography: a report from the Doppler Quantification Task Force of the Nomenclature and Standards Committee of the American Society of Echocardiography.J Am Soc Echocardiogr. 2002;15(2):167-84. [PubMed: 11836492].

12. Schiller NB, Shah PM, Crawford M, DeMaria A, Devereux R, Feigenbaum $\mathrm{H}$, et al. Recommendations for quantitation of the left ventricle by two-dimensional echocardiography. American Society of Echocardiography Committee on Standards, Subcommittee on Quantitation of Two-Dimensional Echocardiograms. J Am Soc Echocardiogr. 1989;2(5):358-67. [PubMed: 2698218].

13. Miller D, Farah MG, Liner A, Fox K, Schluchter M, Hoit BD. The relation between quantitative right ventricular ejection fraction and indices of tricuspid annular motion and myocardial performance.J Am Soc Echocardiogr. 2004;17(5):443-7. doi: 10.1016/j.echo.2004.01.010. [PubMed: 15122184].

14. Eidem BW, McMahon CJ, Cohen RR, Wu J, Finkelshteyn I, Kovalchin JP, et al. Impact of cardiac growth on Doppler tissue imaging velocities: a study in healthy children. J Am Soc Echocardiogr. 2004;17(3):212-21. doi: 10.1016/j.echo.2003.12.005. [PubMed: 14981417].

15. Westwood M, Anderson LJ, Firmin DN, Gatehouse PD, Charrier CC, Wonke B, et al. A single breath-hold multiecho $\mathrm{T} 2^{*}$ cardiovascular magnetic resonance technique for diagnosis of myocardial iron overload. J Magn Reson Imaging. 2003;18(1):33-9. doi: 10.1002/jmri.10332. [PubMed: 12815637].

16. Wood JC. Impact of iron assessment by MRI. Hematology Am Soc Hematol Educ Program. 2011;2011:443-50. doi: 10.1182/asheducation2011.1.443. [PubMed: 22160072].

17. Carpenter JP, He T, Kirk P, Roughton M, Anderson LJ, de Noronha $\mathrm{SV}$, et al. On $\mathrm{T}^{*}$ magnetic resonance and cardiac iron. Circulation. 2011;123(14):1519-28. doi: 10.1161/CIRCULATIONAHA.110.007641. [PubMed: 21444881].

18. Buja LM, Roberts WC. Iron in the heart. Etiology and clinical significance. Am J Med. 1971;51(2):209-21. [PubMed: 5095527].

19. Kyriacou K, Michaelides Y, Senkus R, Simamonian K, Pavlides N, Antoniades L, et al. Ultrastructural pathology of the heart in patients with beta-thalassaemia major. Ultrastruct Pathol. 2000;24(2):75-81. [PubMed: 10808552].

20. Louie EK, Lin SS, Reynertson SI, Brundage BH, Levitsky S, Rich S. Pressure and volume loading of the right ventricle have opposite effects on left ventricular ejection fraction. Circulation. 1995;92(4):819-24. [PubMed: 7641362].

21. Barosi G, Arbustini E, Gavazzi A, Grasso M, Pucci A. Myocardial iron grading by endomyocardial biopsy. A clinico-pathologic study on iron overloaded patients. Eur J Haematol. 1989;42(4):382-8. [PubMed: 2470615].

22. Hahalis G, Manolis AS, Gerasimidou I, Alexopoulos D, Sitafidis G, Kourakli A, et al. Right ventricular diastolic function in betathalassemia major: echocardiographic and clinical correlates. $\mathrm{Am}$ Heart J. 2001;141(3):428-34. doi: 10.1067/mhj.2001.113077. [PubMed: 11231441].

23. Saxena N, Rajagopalan N, Edelman K, Lopez-Candales A. Tricuspid annular systolic velocity: a useful measurement in determining right ventricular systolic function regardless of pulmonary artery pressures. Echocardiography. 2006;23(9):750-5. doi: 10.1111/j.15408175.2006.00305.x. [PubMed: 16999693].

24. Hahalis G, Manolis AS, Apostolopoulos D, Alexopoulos D, Vagenakis AG, Zoumbos NC. Right ventricular cardiomyopathy in beta-thalassaemia major. Eur Heart J. 2002;23(2):147-56. doi: 10.1053/euhj.2001.2709. [PubMed: 11785997]. 
25. Noori NM, Mehralizadeh S. Echocardiographic evaluation of systolic and diastolic heart function in patients suffering from betathalassemia major aged 5-10 years at the Zahedan Research Cen- ter for Children and Adolescent Health. Anadolu Kardiyol Derg. 2010;10(2):150-3. doi: 10.5152/akd.2010.041. [PubMed: 20382615]. 